\title{
Miniaturized SIW Bandpass Filter Based on TSV Technology for THz Applications
}

DOI:

10.1109/TTHZ.2020.2974091

\section{Document Version}

Accepted author manuscript

Link to publication record in Manchester Research Explorer

\section{Citation for published version (APA):}

Wang, F., Pavlidis, V., \& Yu, N. (2020). Miniaturized SIW Bandpass Filter Based on TSV Technology for THz Applications. IEEE Transactions on Terahertz Science and Technology.

https://doi.org/10.1109/TTHZ.2020.2974091

\section{Published in:}

IEEE Transactions on Terahertz Science and Technology

\section{Citing this paper}

Please note that where the full-text provided on Manchester Research Explorer is the Author Accepted Manuscript or Proof version this may differ from the final Published version. If citing, it is advised that you check and use the publisher's definitive version.

\section{General rights}

Copyright and moral rights for the publications made accessible in the Research Explorer are retained by the authors and/or other copyright owners and it is a condition of accessing publications that users recognise and abide by the legal requirements associated with these rights.

\section{Takedown policy}

If you believe that this document breaches copyright please refer to the University of Manchester's Takedown Procedures [http://man.ac.uk/04Y6Bo] or contact uml.scholarlycommunications@manchester.ac.uk providing relevant details, so we can investigate your claim.

\section{OPEN ACCESS}




\title{
Miniaturized SIW Bandpass Filter Based on TSV Technology for THz Applications
}

\author{
Fengjuan Wang, Member, IEEE, Vasilis F. Pavlidis, Senior Member, IEEE, and Ningmei Yu, Member, IEEE
}

\begin{abstract}
A miniaturized substrate integrated waveguide (SIW) bandpass filter with an area of $0.682 \times 0.210 \mathrm{~mm}^{2}$ is proposed based on Through-Silicon Via (TSV) technology for terahertz (THz) applications. The design method of the $\mathrm{THz}$ cavity filter based on rectangular TSV is introduced and the filtering characteristics are investigated by the finite element method (FEM) and mode matching method (MMM). The rectangular TSV is substituted by cylindrical structures and the THz cavity filter is fabricated and measured in order to investigate the possibility of integration with typical 3D IC manufacturing processes. The cavity filter utilizing cylindrical TSV exhibits a bandwidth of $0.051 \mathrm{THz}$ centered at $0.331 \mathrm{THz}$, an insertion loss of $1.5 \mathrm{~dB}$, and a reflection of higher than $15 \mathrm{~dB}$ in the passband.
\end{abstract}

Index Terms-Bandpass, cavity filter, substrate integrated waveguide (SIW), terahertz (THz), through-silicon via (TSV)

\section{INTRODUCTION}

$\mathrm{T}$ erahertz (THz) frequencies are broadly applied in civil and military domains. For $\mathrm{THz}$ systems, rectangular waveguides remain an important transmission medium to realize passive components, such as filters, power dividers, and couplers [1]. Rectangular waveguide filters are always superior to the planar transmission line filters due to lower losses, higher $Q$ factor, and higher power management capacities, as well as better physical robustness [2]. Unfortunately, the waveguide filter dimension decreases as the frequency increases. Although standard (micro)machining techniques can be used to fabricate these THz filters, accuracy and machining tolerances remain an issue [3]. On the other hand, the waveguide filter is usually not compatible with traditional planar silicon process for on-chip integration.

Substrate integrated waveguides (SIWs) have become an emerging transmission structure that attracts significant interest due to its advantages of high $Q$ factor, high power handling capability, low loss, and low cost [4]. However, this waveguide is usually fabricated with a printed circuit board (PCB) or low temperature co-fired ceramic (LTCC) [5]-[7], which is not appropriate for on-chip integration. Meanwhile, operating traditional SIWs into $\mathrm{THz}$ frequencies is challenging due to the large physical dimension of these waveguides.

This work was supported by the National Natural Science Foundation of China under Grant nos. 61774127 and 61771388.

Fengjuan Wang and Ningmei Yu are with the School of Automation and Information Engineering, Xi'an University of Technology, Xi'an 710048, China (email: wfjxiao4@163.com).

Vasilis F. Pavlidis is with the Advanced Processor Technologies Group, Department of Computer Science, the University of Manchester.
Alternatively, Through-Silicon Via (TSV), which is a key

component for three-dimensional integrated circuits (3D ICs), demonstrates high-precision trench etching and metal filling on the order of micrometers, thereby raising significant research interest [8], [9]. Also, since TSV can interconnect other planar devices by re-distribution layers (RDLs) [10], these structures can be integrated with standard CMOS ICs. Therefore, these appealing characteristics make TSV technology a good candidate for miniaturization and integration of passive devices. Indeed, several TSV-based passive devices have been proposed [11]-[13].

In this paper, a miniaturized SIW cavity bandpass filter for $\mathrm{THz}$ applications utilizing TSV technology is proposed and verified. Firstly, the filter based on rectangular TSV with a simple structure is designed and analyzed in Section II. The rectangular TSV are substituted with cylindrical in order to be integrated with a typical 3D IC process and the filter is fabricated and measured in Section III. Some conclusions are drawn in Section IV.

\section{THZ BANDPASS FILTER BASED ON RECTANGULAR TSV}

The structure and design of the new TSV-based SIW are described in this section. The structure of $\mathrm{THz}$ bandpass cavity filter based on rectangular TSV is illustrated in Fig. 1. Here, the top metal is pulled up for the sake of observation. There are six pairs of rectangle TSV iris, forming five resonators. The proposed method for the design of SIW is discussed in subsection II-A and the resulting characteristics of the SIW are investigated in subsection II-B, respectively.

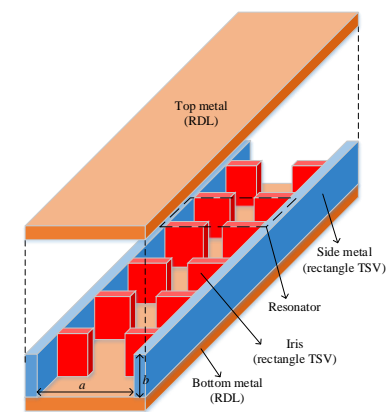

(a)

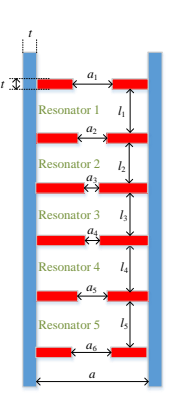

(b)
Fig. 1. (a) Three-dimensional and (b) cross-sectional view of $\mathrm{THz}$ cavity bandpass filter based on rectangular TSV.

\section{A. Design method}

The iris of TSV THz filter is equivalent to a $K$ impedance transformer, and the $K$ impedance transformer form of the equivalent circuit of the filter can be obtained from [14]. Each 
$K$ impedance transformer is equivalent to a T-network, including a series inductance $X_{s}$, a shunt inductance $X_{p}$, and a phase $\phi / 2$. According to the performance requirements, the theoretical impedance of $K$ impedance transformer $K / Z_{0}$ can be obtained. By employing HFSS [15], the relationship of impedance $K / Z_{0}$ and the width of the iris window $W$ is determined, according to which, $W$ is obtained combined with the theoretical value of $K / Z_{0}$. The length of $i^{\text {th }}$ resonator, $l_{i}$ can be determined by the relationship between $K$ and $l_{i}$ [14]. Through these steps, all of the structure parameters of the filter are initially determined. Fine-tuning of the structural parameters based on the mode matching method (MMM) follows. MMM is a fast numerical method compared to computationally expensive FEM simulations with EM solvers.

Using the method described above, the structural parameters of the proposed $\mathrm{THz}$ filter are obtained. The internal cross-sectional area $(a \times b)$ is $200 \mu \mathrm{m} \times 100 \mu \mathrm{m}$. The thickness of TSV iris and side metal $(t)$ is $10 \mu \mathrm{m}$. The thickness of RDL is $5 \mu \mathrm{m}$. The length of resonators $\left(l_{i}, i=1-5\right)$ are $125 \mu \mathrm{m}, 143 \mu \mathrm{m}$, $146 \mu \mathrm{m}, 143 \mu \mathrm{m}$, and $125 \mu \mathrm{m}$, respectively. The width of the iris windows $\left(a_{\mathrm{i}}, i=1-6\right)$ are $115 \mu \mathrm{m}, 85 \mu \mathrm{m}, 78 \mu \mathrm{m}, 78 \mu \mathrm{m}, 85$ $\mu \mathrm{m}$, and $115 \mu \mathrm{m}$, respectively. Therefore, the core area occupied by the THz filter is only $0.682 \mathrm{~mm} \times 0.210 \mathrm{~mm}$.

\section{B. Filtering characteristics}

In this subsection, both FEM and MMM are used to investigate the filtering characteristics of the proposed $\mathrm{THz}$ filter. The $S$-parameters of the proposed $\mathrm{THz}$ cavity filter are shown in Fig. 2. The $\mathrm{THz}$ filter exhibits a bandwidth of 0.05 $\mathrm{THz}$ centered at $0.336 \mathrm{THz}$, and an insertion loss of $0.01 \mathrm{~dB}$.

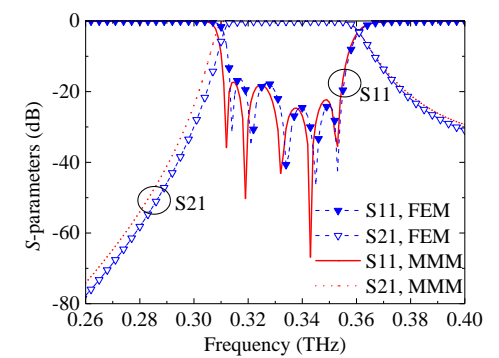

Fig. 2. $S$-parameters of the proposed THz filter based on rectangular TSV.

\section{THZ BANDPASS FILTER BASED ON CYLINDRICAL TSV}

In order to integrate the proposed filter with conventional 3D ICs, common cylindrical TSVs are utilized instead of rectangular TSVs, as shown in Fig. 3. According to the design rules proposed in [4] where the electromagnetic leakage is considered and the requirements of the TSV fabrication process, the diameter and pitch of the cylindrical TSV are selected as $10 \mu \mathrm{m}$ and $20 \mu \mathrm{m}$, respectively. In addition, the aspect ratio of cylindrical TSV is 10:1. The other structural parameters are the same as those used for the filter in Section II. In this section, the prototype filter based on cylindrical TSV is fabricated and measured as described in subsections III-A and III-B, respectively.

\section{A. Fabrication and measurement}

In this subsection, the $\mathrm{THz}$ cavity bandpass filter based on cylindrical TSV is fabricated in high-resistivity silicon substrate (dielectric constant of 11.9 and resistivity of 1000 $\Omega \bullet \mathrm{cm}$ ) with standard TSV process, described in detail in [11]. The scanning electron microscope (SEM) photo of the cross-section view of the THz cavity filter is depicted in Fig. 4. The SEM photo of few TSVs is also provided.

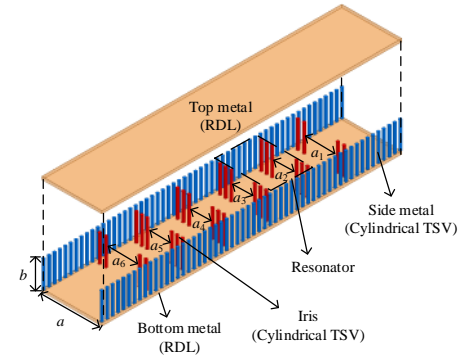

Fig. 3. Three-dimensional view of the THz cavity bandpass filter based on cylindrical TSV.

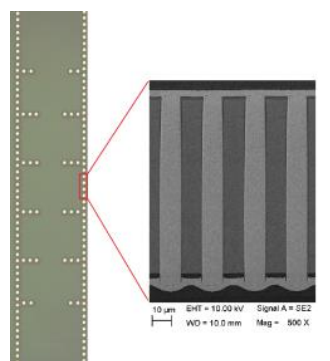

Fig. 4. SEM photographs of cross-section view of $\mathrm{THz}$ cavity filter and partial TSVs.

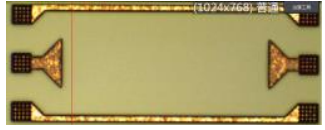

(a)

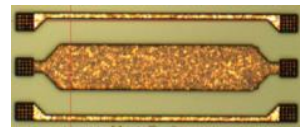

(b)
Fig. 5. Measurement structure of the proposed $\mathrm{THz}$ cavity filter. (a) Open structure and (b) short or device-under-test structure.

The test method in [16] is utilized to measure the $S$-parameters of the $\mathrm{THz}$ cavity bandpass filter based on cylindrical TSV. Since the measurement system is restricted above circa $100 \mathrm{GHz}$, the $S$-parameters of the proposed $\mathrm{THz}$ filter based on cylindrical TSV are investigated with the simplified power-loss method, which is adequate for the functional evaluation and inexpensive [16]. In order to eliminate the effect of the non-ideal factors in the measurement procedure, the open-short de-embedding method is utilized [17]. The measurement structure for the proposed $\mathrm{THz}$ cavity filter, including the open, short, and device-under-test structures are illustrated in Fig. 5. As the short and device-under-test structures are similar, only one figure for both cases is shown (see Fig. 5 (b)). An Agilent N5244A vector network analyzer is employed to evaluate the $S$-parameters of $\mathrm{THz}$ cavity filter.

\section{B. Results and discussion}

Fig. 6 shows the measured and simulated responses of the proposed $\mathrm{THz}$ cavity filter based on cylindrical TSV between $0.26 \mathrm{THz}$ and $0.40 \mathrm{THz}$. The non-ideal fabrication process, such as the non-uniform thickness of RDL and the roughness of TSV sidewalls, leads to scattering during signal transmission. So the measurement results have some performance deviation compared with the ideal simulation results. However, as shown 
in Table I, the errors of IL and RL between the results of FEM and measurement are less than $1 \mathrm{~dB}$, which is acceptable. The cavity filter based on cylindrical TSV exhibits a real bandwidth of $0.051 \mathrm{THz}$ centered at $0.331 \mathrm{THz}$ with an insertion loss of $1.5 \mathrm{~dB}$, and a reflection higher than $15 \mathrm{~dB}$ in the passband. The $S$-parameters of the filter based on rectangular TSV are also given in Fig.6 for comparison. The filter based on cylindrical TSV demonstrates worse filtering characteristics than the rectangular TSV due to the phenomenon of electromagnetic leakage from the gaps between cylindrical TSVs due to the required TSV pitch determined by the TSV fabrication process.

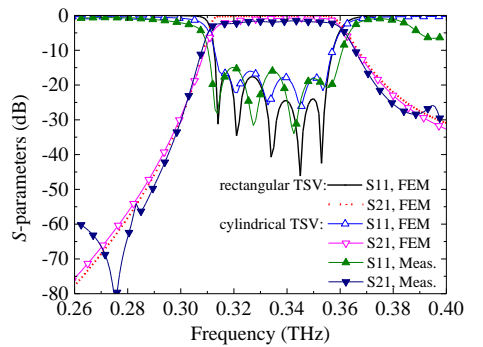

Fig. 6. $S$-parameters of the proposed $\mathrm{THz}$ filter based on rectangular and cylindrical TSVs.

The characteristics of the proposed $\mathrm{THz}$ filter are compared with related works as listed in Table I. Note that the proposed filter exhibits ultra-compact size and superior filtering characteristics. The reason is given as follows. The TSV-based hairpin filter in [18] has higher electromagnetic leakage since the operation of this filter is based on the electromagnetic coupling between TSVs, while the TSV-based SIW filter utilizes the electromagnetic fields propagating in the filter. The two-layer Through-Dielectric Via (TDV)-based SIW filter in [19] is of third order, while the filter in this work is of fifth order. The fourth-order SIW filter in [20] is based on LTCC, which is inherently larger than TSV and operates in lower frequencies.

TABLE I. COMPARISON WITH RELATED THZ FILTERS

\begin{tabular}{|c|c|c|c|c|c|c|c|}
\hline \multirow{2}{*}{ Filters } & \multirow{2}{*}{ Method } & \multirow{2}{*}{$\begin{array}{c}\mathrm{CF} \\
(\mathrm{THz})\end{array}$} & \multirow{2}{*}{$\begin{array}{c}\text { BW } \\
(\mathrm{THz}) \\
\end{array}$} & \multirow{2}{*}{$\begin{array}{c}\text { IL } \\
\text { (dB) }\end{array}$} & \multirow{2}{*}{$\begin{array}{l}\mathrm{RL} \\
(\mathrm{dB})\end{array}$} & \multicolumn{2}{|c|}{ Size } \\
\hline & & & & & & $\left(\mathrm{mm}^{2}\right)$ & $\lambda_{g}^{2}$ \\
\hline [18] & FEM & 0.125 & 0.04 & 6.8 & 8 & $0.3 \times 0.2$ & $0.43 \times 0.29$ \\
\hline [19] & FEM & 0.16 & 0.02 & 1.5 & 10 & $0.9 \times 0.325 \times 2$ & $2.25 \times 0.81$ \\
\hline [20] & Meas. & 0.14 & 0.023 & 2.4 & 11 & r & $2.90 \times 1.27$ \\
\hline This work $1^{*}$ & FEM & 0.336 & 0.050 & 0.01 & 16 & \multirow{3}{*}{$0.682 \times 0.21$} & \multirow{3}{*}{$2.60 \times 0.80$} \\
\hline \multirow{2}{*}{ This work $2^{* *}$} & FEM & 0.337 & 0.046 & 0.7 & 16 & & \\
\hline & Meas. & 0.331 & 0.051 & 1.5 & 15 & & \\
\hline
\end{tabular}

"This work 1 represents the filter based on rectangular TSV.

${ }^{* *}$ This work 2 represents the filter based on cylindrical TSV.

\section{CONCLUSION}

The SIW cavity $\mathrm{THz}$ bandpass filters based on rectangular and cylindrical TSVs are proposed. For the filter based on rectangular TSV, the FEM and MMM techniques are used to investigate the filtering characteristics. The filter based on cylindrical TSV is fabricated and measured demonstrating the integration of this filter with conventional 3D ICs. The results show that the proposed filters demonstrate higher performance over state-of-the-art SIWs.

\section{REFERENCES}

[1] O. Sushko, M. Pigeon, R. S. Donnan, T. Kreouzis, C. G. Parini, and R. Dubrovka, "Comparative Study of Sub-THz FSS Filters Fabricated by Inkjet Printing, Microprecision Material Printing, and Photolithography," IEEE Transactions on Terahertz Science and Technology, vol. 7, no. 2, pp. 184-190, March 2017.

[2] E. A. R.-Nastrucci, J. T. Nussbaum, N. B. Crane, and T. M. Weller, "Ka-band characterization of binder jetting for 3-D printing of metallic rectangular waveguide circuits and antennas," IEEE Trans. Microw. Theory Tech., vol. 65, no.9, pp. 3099 - 3108, Sept. 2017.

[3] K. M. K. H. Leong, K. Hennig, C. Zhang, R. Elmadjian, Z. Zhou, B. S. Gorospe, P. P. Chang-Chien, V. Radisic, and W. R. Deal, "WR1. 5 Silicon Micromachined Waveguide Components and Active Circuit Integration Methodology," IEEE Trans. Microw. Theory Tech., vol. 60, no.4, pp. 998 - 1005, Apr. 2012.

[4] F. Xu and K. Wu, "Guided-Wave and Leakage Characteristics of Substrate Integrated Waveguide," IEEE Trans. Microw. Theory Tech., vol. 35, no.1, pp. 66 - 73, Jan. 2005

[5] Q.-L. Zhang, B.-Z.Wang, D.-S. Zhao, and K. Wu, "A compact half-mode substrate integrated waveguide bandpass filter with wide out-of-band rejection," IEEE Microw. Wireless Components Letters, vol.26, no.7, pp. 576 - 578, Jul. 2016.

[6] P. Wu, J. Liu, and Q. Xue, "Wideband excitation technology of TE20 mode substrate integrated waveguide (SIW) and its applications," IEEE Trans. Microw. Theory Tech., vol. 63, no.6, pp. 1863 - 1874, Jun. 2015.

[7] W. Yang, Y. Yang, W. Che, C. Fan, and Q. Xue, "94-GHz compact 2-D multibeam LTCC antenna based on multifolded SIW beam-forming Network," IEEE Trans. Antennas Propag., vol. 65, no.8, pp. 4328 - 4333, Aug. 2017.

[8] X. Yin, Z. Zhu, Y. Yang, and R. Ding, "Metal proportion optimization of annular through-silicon via considering temperature and keep-out zone," IEEE Trans. Compon. Packag. Manuf. Technol., vol. 5, no. 8, pp. 10931099, Aug. 2015.

[9] X. Yin, Z. Zhu, Y. Yang, and R. Ding, "Effectiveness of $p+$ layer in mitigating substrate noise induced by through-silicon via for microwave applications," IEEE Microwave Wireless Components Letters, vol. 26, no.9, pp. 687 - 689 , Sep. 2016.

[10] L. Qian, Y. Xia, X. He, K. Qian, and J. Wang. "Electrical modeling and characterization of silicon-core coaxial through-silicon vias in 3-D integration," IEEE Trans. Compon. Packag. Manuf. Technol., vol. 8, no. 8, pp. 1336 - 1343, Aug. 2018

[11] X. Yin, Z. Zhu, Y. Liu, Q. Lu, X. Liu, and Y. Yang. "Ultra-compact TSV-based $L-C$ low-pass filter with stopband up to $40 \mathrm{GHz}$ for microwave application," IEEE Trans. Microw. Theory Tech., vol. 67, no. 2, pp.738 - 745, Feb. 2019

[12] F. Wang and N. Yu. "An ultracompact butterworth low-pass filter based on coaxial through-silicon vias". IEEE Trans. Very Large Scale Integr. (VLSI) Syst., vol. 25, no. 3, pp. 1164 - 1167, Nov. 2017

[13] X. Yin, Z. Zhu, Y. Yang et al., "A compact passive resonator based on through-silicon via technology for microwave applications". In IEEE MTT-S Int. Wireless Symp., Jul. 2018. pp. 1-3

[14] R. J. Cameron, R. Mansour, and C. M. Kudsia, Microwave filters for communication systems fundamentals, design and applications, 1st ed, Wiley-Interscience, 2007.

[15] (2019)https://www.ansys.com/products/electronics/ansys-hfss

[16] X. H. Zhao, J. F. Bao, G. C. Shan, Y. J. Du, Y. B. Zheng, Y. Wen, and C. H. Shek, "D-band micromachined silicon rectangular waveguide filter," IEEE Microwave Wireless Components Letters, vol. 22, no. 5, pp. 230-232, May 2012.

[17] L. Li, K. Ma, and S. Mou, "Modeling of new spiral inductor based on substrate integrated suspended line technology," IEEE Trans. Microw. Theory Techn., vol. 65, no. 8, pp. 2672-2680, Aug. 2017.

[18] S. Hu, L.Wang, Y.-Z. Xiong, T. G. Lim, B. Zhang, J. Shi, and X. Yuan, "TSV technology for millimeter-wave and terahertz design and applications," IEEE Trans. Compon. Packag. Manuf. Technol., vol. 1, no. 2, pp. 260-267, Feb. 2011.

[19] X. Liu, Z. Zhu, Y. Liu, Q. Lu, X. Yin, and Y. Yang, "Wideband Substrate Integrated Waveguide Bandpass Filter Based on 3-D ICs," IEEE Trans. Compon. Packag. Manuf. Technol., vol. 9, no. 4, pp. 728-735, April 2019.

[20] K. Wang, S. Wong, G. Sun, Z. N. Chen, L. Zhu, and Q. Chu, "Synthesis Method for Substrate-Integrated Waveguide Bandpass Filter With Even-Order Chebyshev Response," IEEE Trans. Compon. Packag. Manuf. Technol., vol. 6, no. 1, pp. 126-135, Jan. 2016. 